\title{
O VOICE ONSET TIME DAS PLOSIVAS DO PORTUGUÊS BRASILEIRO EM CONTATO COM O HUNSRÜCKISCH E SEU DESVOZEAMENTO VARIÁVEL
}

\author{
VOICE ONSET TIME DE LAS PLOSIVAS DEL PORTUGUÉS BRASILEÑO EN CONTACTO CON EL \\ HUNSRÜCKISCH Y SU DESONORIZACIÓN VARIABLE
}

\author{
THE VOICE ONSET TIME OF PLOSIVES IN BRAZILIAN PORTUGUESE IN CONTACT WITH \\ HUNSRÜCKISCH AND THEIR VARIABLE DEVOICING
}

\author{
Cláudia Camila Lara" \\ Elisa Battisti** \\ Universidade Federal do Rio Grande do Sul - UFRGS, Porto Alegre, BR
}

\begin{abstract}
RESUMO: O presente estudo volta-se ao Voice Onset Time (VOT) de plosivas desvozeadas no português brasileiro (PB) em contato com o Hunsrückisch, língua minoritária alemã falada na comunidade de Glória, zona rural do município de Estrela (RS). Os objetivos são (a) apresentar algumas características acústicas de plosivas do PB de contato, na tentativa de confirmar o desvozeamento variável percebido de oitiva em um estudo sociolinguístico (LARA, 2013); e (b) verificar se os valores de VOT conformam-se ao padrão do Hunsrückisch, ao do PB, ou se são únicos à língua de contato (MOHANAN e MOHANAN, 2003). Realiza-se análise acústica das plosivas com o programa computacional PRAAT (BOERSMA; WEENINK, 2013), produzidas por uma informante adulta (LARA, 2013). A análise acústica confirma o desvozeamento captado de oitiva. Mostra que os valores de VOT não se conformam ao padrão de desvozeamento do Hunsrückisch, aproximando-se ao do $\mathrm{PB}$, mas parecendo ser específicos ao PB de contato.
\end{abstract}

PALAVRAS-CHAVE: variação; contato linguístico; plosivas; VOT.

RESUMEN: El presente estudio está direccionado al Voice Onset Time (VOT) de las plosivas desonorizadas en el portugués brasileño (PB) en contacto con el Hunsrückisch, Lengua Alemana minoritaria hablada en la comunidad de Glória, Zona rural del Municipio de Estrela (RS). Los objetivos son (a) mostrar algunas de las características acústicas de las plosivas del PB de contacto en un intento de confirmar la desonorización variable percibida por el oído en un estudio sociolingüístico (LARA, 2013) y (b) verificar si los valores de VOT cumplen con el padrón del Hunsrückisch, a del PB, o si son únicos al lengua de contacto (MOHANAN e MOHANAN, 2003). Se llevó a cabo análisis acústico de las plosivas con el programa informático PRAAT (BOERSMA; WEENINK, 2013), producidas por una informante adulta (LARA, 2013). El análisis acústico confirma la desonorización percibida por la escucha. Muestra que los valores VOT no se ajustan al padrón de la desonorización del Hunsrückisch, aproximándose al del PB, pero pareciendo ser específicos al PB de contacto.

PALABRAS-CLAVE: variación; contacto de lenguas; plosivas; VOT.

ABSTRACT: The study is about the Voice Onset Time (VOT) of devoiced plosives in Brazilian Portuguese (BP) spoken by descendants of German immigrants in Gloria, a rural community in Estrela city, Rio Grande do Sul, Brazil. In Gloria, BP is in contact with Hunsrückisch, a German dialect. The study aims at (a) showing some acoustic characteristics of BP plosives in the contact variety in order to confirm the variable devoicing perceived by hearing in a sociolinguistic study (LARA, 2013); and (b) verifying whether the VOT values of the plosives conform to the Hunsrückisch VOT pattern or are unique to the contact language (MOHANAN e MOHANAN, 2003). Acoustic analysis of plosives is carried out with the computer program PRAAT (BOERSMA; WEENINK, 2013). Data from an adult informant of Lara (2013) are used. The acoustic analysis confirms the devoicing perceived by hearing. It shows that VOT values of devoiced plosives in the contact language are different from the Hunsrückisch VOT pattern and close to the BP VOT pattern, but are peculiar to the contact language.

KEYWORDS: variation; language contact; plosives; VOT.

\section{INTRODUÇÃO}

Os estudos de variação e mudança fonológica na linha laboviana (LABOV, 1972) tradicionalmente levantam, por oitiva, dados relevantes de entrevistas sociolinguísticas. Esse procedimento, que implica ouvir as formas e assim verificar a aplicação, ou não, de um processo variável do mesmo modo que faz o

\footnotetext{
* Doutoranda do Programa de Pós-Graduação em Letras da UFRGS, área Estudos da Linguagem, especialidade Teoria e Análise Linguística, linha Fonologia e Morfologia. Email: ccamilalara@gmail.com.

** Professora do Programa de Pós-Graduação em Letras da UFRGS, área Estudos da Linguagem, especialidade Teoria e Análise Linguística, linha Fonologia e Morfologia. Bolsista de Produtividade do CNPq. Email: battisti.elisa@gmail.com
} 
falante-ouvinte em suas interações diárias, é suficiente para o alcance dos objetivos de grande parte dos estudos em tal linha de investigação. Há, no entanto, objetos de análise de regra variável laboviana que se beneficiariam da utilização adicional de outros procedimentos, como aqueles envolvidos em estudos fonéticos de natureza acústica. É o que se pretende explorar no presente estudo ${ }^{1}$, aproximando-se, assim, análise acústica e análise de variação fonológica.

O objeto de estudo é o desvozeamento de plosivas vozeadas do português brasileiro (PB) em contato com a língua minoritária alemã, Hunsrückisch, realização variável (gravador cravador, dezoito tezoito, igreja icreja) na fala de bilíngues português-alemão e recorrente nos estereótipos de descendentes de alemães do Sul do Brasil. Lara (2013) considerou apenas plosivas bilabiais para realizar análise de regra variável tanto do desvozeamento quanto do vozeamento (pudim budim) de dados levantados de oitiva de uma amostra da fala de Glória, comunidade da zona rural do município de Estrela, Rio Grande do Sul, onde o bilinguismo se verifica. O baixo índice de aplicação de regra $(1,6 \%)$, de um lado, e o fato de o desvozeamento/vozeamento dessas plosivas ser sutil para um exame de oitiva, de outro, sugeriram a necessidade de recorrer a medidas acústicas de dados no que se refere especificamente ao desvozeamento, processo que efetivamente ocorre na comunidade. Lara (2013, p.62) afirma que, em Glória, a "vozeada tende a sofrer desvozeamento, [...] a plosiva bilabial” praticamente não se altera em vozeamento. “...há no Hunsrückisch um processo ativo de desvozeamento das plosivas que provavelmente se estendeu ao português local".

Interessa-nos, então, mensurar acusticamente o Voice Onset Time (VOT), isto é, a duração do intervalo de tempo entre a soltura da plosiva e o início da vibração das pregas vocais (BANDEIRA; ZIMMER, 2011) de alguns dados daquele estudo anterior. O VOT é um atributo fonético considerado especialmente na distinção de plosivas vozeadas e desvozeadas, em contextos linguísticos (posição na palavra, por exemplo) em que tal distinção é complexa. É o caso do inglês, em que as plosivas / b d g/ distinguem-se de / p t k/ no meio de palavra pela sua realização vozeada. Já em início de palavra, /b d g/ podem realizar-se variavelmente com vozeamento parcial e até desvozeamento. Essa gradiência no vozeamento pode ser captada pela medida de VOT.

A literatura da área apresenta três tipos principais de VOT com áreas de valores que os especificam, como explicam Klein (1999), Reis e Nobre-Oliveira (2007), Alves (2011) e Cristofolini (2013), dentre muitos outros, baseando-se em Lisker e Abramson (1964), num estudo envolvendo 11 línguas. Os tipos principais de VOT são:

- pré-sonorização: quando o início da sonorização/vozeamento é anterior à soltura da oclusão. É característica de segmentos plosivos vozeados. É também chamado de VOT negativo (VOT (-)) porque é representado por valores negativos, que apenas indicam a antecedência da sonorização à soltura da oclusão. Varia entre $-125 \mathrm{~ms} \mathrm{e}-75 \mathrm{~ms}^{2}$.

- retardo curto: o início da sonorização/vozeamento e a soltura da oclusão ou são simultâneos (VOT zero), ou a sonorização segue imediatamente a soltura da oclusão, sem aspiração. A denominação VOT zero devese à simultaneidade entre o início do vozeamento e a soltura da oclusão. Varia entre 0 e 35 ms.

- retardo longo: o início da sonorização/vozeamento começa após a soltura da oclusão, pois há um atraso entre a soltura e o início do vozeamento, o que é característico de plosivas produzidas com aspiração. É chamado também VOT positivo (VOT $(+)$ ). Varia entre $+35 \mathrm{~ms}$ e $+100 \mathrm{~ms}$.

O português brasileiro é conhecido por apresentar contraste entre plosivas vozeadas e não-vozeadas, caracterizando-se, respectivamente, pela pré-sonorização e pelo retardo curto.

As medidas de VOT podem variar de uma língua para outra e também em razão do segmento seguinte à plosiva. Dentre as explicações para essas diferenças nas medidas está a de Hardcastle (1973), conforme Cho e Ladefoged (1999): quanto mais rápido o movimento articulatório, menor o VOT. Além da velocidade do movimento articulatório, aspectos aerodinâmicos e diferenças na massa dos articuladores podem influenciar as medidas. Em razão dessa variabilidade intrínseca, e pelo fato de nosso objeto de investigação emergir no

\footnotetext{
${ }^{1}$ Agradecemos à Izabel Christine Seara (UFSC) a leitura cuidadosa do manuscrito e as importantes sugestões de ajuste. Qualquer equívoco que eventualmente tenha permanecido no artigo é de nossa inteira responsabilidade.

${ }^{2}$ ms é o símbolo de milissegundo.
} 
contexto de línguas em contato (PB e Hunsrückisch) com possíveis diferenças de VOT, surgem as questões do presente estudo: as realizações desvozeadas de plosivas no português brasileiro captadas de oitiva para o estudo de Lara (2013) são, de fato, realizadas sem vozeamento? E o padrão de desvozeamento nas realizações variáveis resulta da transferência do padrão da língua minoritária (Hunsrückisch) para a língua majoritária (PB)? Essa última questão ganha especial relevo numa linha de investigação como a de Mohanan e Mohanan (2003), sobre as propriedades estruturais de línguas em contato em geral, se partilhadas com seu substrato ou superestrato ${ }^{3}$, ou se únicas às línguas em contato.

Nossos objetivos são, então, mostrar algumas características acústicas de plosivas vozeadas do PB em contato com o Hunsrückisch na fala de adultos, para (i) confirmar o desvozeamento captado de oitiva para o estudo de Lara (2013) e (ii) verificar se, na fala em PB, os valores de VOT conformam-se ao padrão da língua minoritária ou ao padrão da língua majoritária, ou se são específicas ao PB de contato (MOHANAN e MOHANAN, 2003).

Usaremos dados provenientes de uma entrevista sociolinguística de Lara (2013). Essa entrevista, como as demais realizadas pela autora, corresponde a uma conversa semidirigida entre pesquisadora e informante. Foi gravada em ambiente natural de fala, sem o isolamento acústico geralmente exigido em estudos fonéticos. Antes que descuido, essa é uma decisão proposital da pesquisa, tomada no intuito de operar com os mesmos dados da oitiva do estudo anterior e validar a análise acústica de dados de fala natural. Mesmo com ruído de fundo nas gravações e outras interferências ambientais, o sinal sonoro, como veremos, manteve integridade suficiente para os propósitos do estudo. Ainda assim, reconhecemos que os resultados obtidos com esses dados podem diferir em alguma medida dos resultados obtidos com dados gravados em laboratório, com instrumentos controlados, o que, no entanto, não deve desfazer a análise aqui empreendida.

Iniciaremos o trabalho por uma caracterização da comunidade de fala envolvida, Glória, no contexto da imigração alemã, e pela abordagem ao contato PB-Hunsrückisch em termos linguísticos e sociais, aí relatando também os resultados de Lara (2013). Depois, revisaremos estudos sobre o VOT de plosivas do PB em contato com falares dialetais alemães. Em seguida, descreveremos os procedimentos metodológicos, apresentaremos e discutiremos os resultados da análise, encerrando o trabalho com nossas conclusões.

\section{A COMUNIDADE DE GLÓRIA, ZONA RURAL DE ESTRELA (RS) E O CONTATO PB- HUNSRÜCKISCH}

O município de Estrela (RS), em cuja zona rural situa-se Glória, foi fundado por imigrantes alemães no século XIX. Segundo Raso, Mello e Altenhofen (2011), a ocupação de terras por imigrantes alemães no Sul do Brasil voltou-se às áreas do interior. A primeira leva destinada ao Rio Grande do Sul chegou a São Leopoldo em 25 de julho de 1824.

Nas novas comunidades, os imigrantes comunicavam-se na língua de seu país de origem e, aos poucos, foram aprendendo o português brasileiro $(\mathrm{PB})$. O Hunsrückisch é uma das variedades dialetais do alemão faladas por eles. Recebeu esse nome porque seus falantes vieram, em sua maioria, da região do Hunsrück, na Alemanha. O que se fala hoje no Sul do Brasil é considerado coiné porque possui traços de diferentes dialetos alemães. Trata-se de um contínuo linguístico de base francônio-renana e francônio-moselana, com características devidas à fusão a outras bases dialetais, bem como ao contato com o PB.

No século XX, o golpe político do Estado Novo (1937-1945) por Getúlio Vargas proibiu qualquer manifestação em língua estrangeira. Iniciou-se um período em que era proibido comunicar-se em variedades da língua alemã e de outras línguas nas colônias de imigrantes. A proibição coincidiu com a Segunda Guerra Mundial (1939-1945).

Para os imigrantes aprenderem o $\mathrm{PB}$, foram enviados às colônias pelo governo brasileiro professores que falavam o PB. Padres e pastores também deviam falar o PB, a fim de estabelecer uma identidade nacional.

\footnotetext{
${ }^{3}$ Substrato é a variedade linguística não dominante que influencia outra variedade, dominante. Superestrato, ao contrário, é a variedade dominante que influencia outra não dominante (CRYSTAL, 2000, p.247). Segundo Mohanan e Mohanan (2003), a tensão entre o substrato e o superestrato pode fazer emergirem padrões linguísticos particulares a eles relacionados, mas peculiares ao offspring ('fruto', 'rebento', 'prole', em inglês), novo sistema resultante do contato.
} 
Apesar dessa iniciativa de nacionalização, os imigrantes acabaram por não aprender efetivamente, nesse período, nem a variedade padrão de suas línguas de origem (alemão padrão, no caso em questão), tampouco o PB.

$\mathrm{Na}$ fala em $\mathrm{PB}$, os imigrantes alemães permaneceram, por muitos anos, com traços linguísticos das variedades dialetais de origem, como o Hunsrückisch. Muitos dos traços linguísticos foram superados e vêm, atualmente, desaparecendo no PB. Porém, percebe-se, ainda, a presença de algumas marcas desse contato. Uma delas verifica-se na realização das plosivas, como a da bilabial desvozeada [p] em lugar da vozeada /b/ e vice-versa.

O estudo de Altenhofen (1990) analisou o papel e o significado da aprendizagem do português, como segunda língua, nas relações sociais dos membros de um grupo minoritário de origem alemã, no município de Harmonia (RS). A interferência dos traços fonológicos desse contato resulta em erros ortográficos dos alunos, na "troca de letras" (ALTENHOFEN, 1990, p. 229). Entre outras trocas, está o caso das plosivas: os alunos não distinguem as consoantes surdas e sonoras por não haver a distinção na língua materna, o Hunsrückisch.

Os problemas de aprendizagem do $\mathrm{PB}$ devidos ao uso do alemão estão centrados em duas das mais importantes esferas da comunidade, a educação e a administração, segundo o autor. Esses problemas manifestam-se no conjunto de atitudes negativas a respeito da língua minoritária, o Hunsrückisch. Proíbese, condena-se e culpa-se o Hunsrückisch, desconsiderando-se o seu valor no grupo. Essas atitudes depreciativas apresentam origens históricas e manifestam-se dependendo do contexto de uso da língua.

No contexto social de Harmonia (RS), o autor, ao investigar as relações interpessoais nas redes de comunicação locais, constatou que a sobrevivência do Hunsrückisch deve-se ao peso das relações em rede do grupo. Caracterizou o grupo rural como "um sistema com uma rede de comunicação de alta densidade e altamente multiplexo, um sistema bastante uniforme, com elevados índices de bilinguismo, aumentando a coesão do grupo, um sistema situado num meio eminentemente rural”. (ALTENHOFEN, 1990, p. 209).

Lara (2013) investigou o desvozeamento/vozeamento variável de plosivas bilabiais vozeadas e não vozeadas no PB falado em Glória, zona rural de Estrela (RS), onde ainda hoje verifica-se o contato PB-Hunsrückisch, embora nem toda a população seja bilíngue. A autora empreendeu análise de regra variável (LABOV, 1972) e de rede social (MILROY, 1987; 2002). Levantou contextos de desvozeamento/vozeamento de vinte e quatro entrevistas sociolinguísticas. Esses dados foram analisadosquantitativamente com os programas computacionais do pacote VARBRUL, para verificar os fatores linguísticos e extralinguísticos que condicionam a aplicação da regra. Os dados foram levantados das entrevistas por oitiva. A proporção total de aplicação de regra foi baixa $(1,6 \%)$, o que não permite afirmar que o processo seja efetivamente variável. Trata-se de um processo residual na comunidade de fala, que tem preferentemente como alvo a plosiva bilabial vozeada e, como promotoras, as mulheres. Os informantes mais velhos (47 anos ou mais) favoreceram a aplicação da regra, bem como os informantes com menor nível de escolaridade (ensino fundamental) e os bilíngues PB-Hunsrückisch. A análise de rede social dos informantes realizada pela autora traz uma explicação para a regressão. A rede é densa e multiplexa. Apesar disso, os informantes centrais na rede, idosos, não difundem a regra variável a seus contatos, jovens. É o caso da informante I.L., que promoveu 101 ocorrências de aplicação da regra, mas cujos contatos na rede (dois membros), apesar da forte ligação, promoveram apenas 2 e 1 ocorrências. Esses contatos são tanto do gênero feminino quanto do masculino, encontram-se nas faixas etárias de 15 a 30 anos e 31 a 46 anos, têm ensino médio e superior e suas ocupações são não-locais. Falam diferentemente dos mais velhos principalmente pelo emprego do PB na zona urbana, onde trabalham.

A informante I.L. representa um grupo de falantes de Glória que ainda mantêm a variação no vozeamento das plosivas bilabiais. É da fala dessa informante que retiramos os dados a serem submetidos à análise de VOT com o programa computacional PRAAT. Pelo padrão variável verificado, interessa-nos, sobretudo, o desvozeamento das plosivas vozeadas. Como veremos adiante, a análise visa não só a confirmar se os dados levantados de oitiva são efetivamente desvozeados, mas também verificar o padrão de VOT dessas consoantes vozeadas, se conforme à língua minoritária (Hunsrückisch) ou à majoritária (PB). Isso revelará se, no padrão em que há transferência de traços da língua minoritária para a majoritária, esses se aproximam mais da fala dialetal ou da fala em PB. Sendo esse último o caso, teremos mais uma evidência de que a regra variável em questão está em franca regressão na comunidade. 


\section{ESTUDOS DE VOT DE PLOSIVAS DO PB EM CONTATO COM FALARES DIALETAIS ALEMÃES}

Não há valores absolutos para o VOT, como vimos na introdução deste trabalho. No entanto, há medidas médias que servem como referência. As medidas encontradas para as plosivas do PB por Istre (1983), por exemplo, são: $12 \mathrm{~ms}$ para [p], $18 \mathrm{~ms}$ para [t], $38 \mathrm{~ms}$ para [k], -39,45 ms para [b], -60,59 ms para [d] e $53,69 \mathrm{~ms}$ para [g].

No estudo de Klein (1999), as médias gerais para as plosivas de retardo curto do PB (a soltura da oclusão e o início do vozeamento são quase simultâneos) foram de $15,58 \mathrm{~ms}$ para [p], 16,69 ms para [t] e de 36,36 ms para [k], e as médias gerais das plosivas para o pré-vozeamento (o início do vozeamento se dá antes da soltura da oclusão, resultando valores negativos de VOT) foram de $-92,27 \mathrm{~ms}$ para [b]; para [d], de -92,07 ms e para [g], $-78,20 \mathrm{~ms}$.

Segundo Alves (2011), as médias de VOT para as plosivas desvozeadas e não aspiradas do PB, de acordo com o ponto de articulação, são: 18,62 ms para [p], 24,15 ms para [t] e 26,92 ms para [k].

Quais seriam as médias de referência para o PB em contato com línguas minoritárias alemãs?

\subsection{Estudos de VOT em contatos linguísticos}

Estudos de VOT no contato linguístico entre PB e línguas de imigração alemã foram realizados por diferentes pesquisadores. Gewehr-Borella (2010) e Weirich e Ferreira-Gonçalves (2012) investigaram o VOT de plosivas no contato PB-Hunsrückisch, Bandeira (2010) e Bandeira e Zimmer (2011), no contato PB-Pomerano".

No Hunsrückisch, Gewehr-Borella (2010) comparou a produção escrita, oral e a percepção de alunos monolíngues falantes do PB sem contato com outra língua, monolíngues falantes do PB que moram em contexto bilíngue e bilíngues PB-Hunsrückisch. Analisou a troca dos grafemas $<\mathrm{p}, \mathrm{b}>,<\mathrm{t}, \mathrm{d}>\mathrm{e}<\mathrm{c}, \mathrm{g}>$, mediu VOTs na fala em PB e em Hunsrückisch, bem como descreveu os dados do teste de percepção. A coleta dos dados foi realizada com alunos do Ensino Fundamental de duas comunidades gaúchas: Rio Grande e Picada Café.

Alguns alunos não apresentaram transferências. Outros, no entanto, apresentaram transferências de dois tipos: grafo-fônico-fonológicas, que ocorreram da fala para a escrita, e transferências fonético-fonológicas, geradas pela dificuldade de perceber as diferenças acústico-articulatórias da L1 e L2 ${ }^{5}$. Por não perceberem alguns fones da forma considerada padrão, os alunos transferiram os padrões distintos de VOT percebidos para sua fala.

Gewehr-Borella (2010) verificou que as medidas dos VOTs dos segmentos [p], [t], [k] tendem a ser maiores nas crianças bilíngues, pela transferência da aspiração presente na língua de imigração Hunsrückisch ao PB. A média do VOT para [p] é de 27,36 ms; para [t], de 23,91 ms e para [k], de 40,85 ms.

Weirich e Ferreira-Gonçalves (2012) investigaram a produção da escrita e a fala de plosivas em início de sílaba por falantes bilíngues e monolíngues. Os padrões de vozeamento de falantes monolíngues e bilíngues em Agudo (RS) foram verificados acusticamente. A análise revelou que há diferenças entre os grupos: o grupo bilíngue produz médias mais altas de VOT em comparação com o grupo monolíngue. As autoras concluíram que o Hunsrückisch influencia o processo de aquisição da escrita do português dos falantes bilíngues. Na fala, a influência é ainda maior: "as variações nos padrões de VOT produzem mudanças sonoras nas produções orais em língua portuguesa dos bilíngues" (WEIRICH; FERREIRA-GONÇALVES, 2012, p.4).

\footnotetext{
${ }^{4}$ Pomerano é uma língua de imigração falada em localidades do Rio Grande do Sul e de outros estados brasileiros por descendentes de alemães da Pomerânia, região que, ao final do século XIX, época da imigração ao Brasil, pertencia ao Reino da Prússia (1701-1918), Estado-membro do Império Alemão a partir de 1871. Os imigrantes pomeranos que vieram para o Sul do Brasil dedicaram-se principalmente ao trabalho agrícola.

${ }^{5}$ L1 e L2 correspondem, respectivamente, à língua materna e segunda língua.
} 
Bandeira (2010) pesquisou o padrão fonético-fonológico no contato PB-Pomerano. Analisou dados de 40 sujeitos, 20 multilíngues de L1 Pomerano, L2 PB e L3 Inglês, e 20 monolíngues de L1 PB. A autora concluiu que os falantes multilíngues transferem os padrões de VOT de sua L1, Pomerano, para a L2, PB, e para a L3, Inglês. As médias de VOT encontradas por Bandeira (2010) na fala de sujeitos monolíngues PB foram de $20 \mathrm{~ms}$ para $[\mathrm{p}], 18 \mathrm{~ms}$ para [t] e de $35 \mathrm{~ms}$ para $[\mathrm{k}]$.

Os estudos revisados, realizados com crianças em fase escolar, atestaram a transferência do padrão de VOT da fala dialetal alemã para a fala em PB. Para a presente análise, fica a questão relativa à fala da informante I.L. de Lara (2013), adulta idosa que, como vimos na seção 2, é a maior promotora do desvozeamento variável em Glória: há desvozeamento com VOT zero, como nas plosivas desvozeadas do PB, ou VOT positivo, como nas plosivas desvozeadas com aspiração do Hunsrückisch, conforme Gewehr-Borella (2010)? Em outras palavras, houve desvozeamento conforme o VOT do PB ou do Hunsrückisch?

A resposta a essa questão poderá subsidiar a explicitação das propriedades estruturais do PB em contato com o Hunsrückisch e o debate sobre as propriedades estruturais de línguas em contato em geral.

\section{PROCEDIMENTOS METODOLÓGICOS}

Os dados de fala analisados foram recortados da entrevista sociolinguística da informante I.L., de Lara (2013). Essa entrevista versava sobre temas do cotidiano, como atividades de trabalho e lazer, a comunidade, culinária, religião. As características sociais da informante estão no Quadro 1.

Quadro 1 - Perfil da informante I.L.

\begin{tabular}{|c|c|c|c|c|}
\hline Sexo & Faixa etária & Escolaridade & Bilinguismo & Ocupação \\
\hline Feminino & $\begin{array}{c}47 \text { anos } \\
\text { ou mais }\end{array}$ & $\begin{array}{c}\text { Nível } \\
\text { fundamental }\end{array}$ & $\begin{array}{c}\text { Bilíngue PB- } \\
\text { Hunsrückisch }\end{array}$ & Local/Aposentado \\
\hline
\end{tabular}

Os dados foram submetidos ao programa PRAAT (BOERSMA; WEENINK, 2013). Consideraram-se os pulsos glotais para confirmar o desvozeamento ou detectar vozeamento no espectrograma. Confirmado o desvozeamento, passou-se à mensuração do VOT.

Numa primeira etapa da análise, procurou-se verificar, considerando-se toda a série de plosivas e ambos os processos (vozeamento e desvozeamento), se de fato o desvozeamento predomina e quais segmentos são majoritariamente afetados pelos processos.

A segunda etapa da análise voltou-se apenas ao desvozeamento. Além do VOT da plosiva /b/ desvozeada, mensurou-se o VOT das plosivas /d/ e /g/, para fins de contraste ${ }^{6}$ e generalização. As palavras-alvo analisadas nessa etapa foram barato, com plosiva inicial /b/, estudar, com plosiva /d/ e grava, com plosiva $/ \mathrm{g} /$. Essas três palavras foram as escolhidas, dentre outras possibilidades, porque, de oitiva, apresentaram desvozeamento da plosiva inicial. Além disso, têm padrões silábicos e prosódicos que se revelaram significativos na análise de regra variável de Lara (2013): trissilábico e pretônico (barato), trissilábico e tônico (estudar e agora). As palavras-alvo foram retiradas da entrevista sociolinguística da informante I.L. nos trechos: "aqui os terreno são mais barato" (03:14), "vão estudar ou vão pro centro" (02:38) e "Ah, tu grava com o celular" (00:16).

\section{RESULTADOS}

Iniciamos a apresentação dos resultados da primeira etapa de análise retomando a observação de Lara (2013) de que o desvozeamento das plosivas bilabiais vozeadas, antes do que o vozeamento das nãovozeadas, é o que se promove em Glória, numa proporção total tão baixa que se poderia afirmar a regressão da regra e seu desaparecimento em poucas gerações.

\footnotetext{
${ }^{6}$ O contraste será estabelecido com as médias de VOT dos demais estudos revisados, do PB: Istre (1983), Klein (1999), Alves (2011) e Cristofolini (2013) e do PB em contato com línguas minoritárias: Gewehr-Borella (2010) e o de Bandeira (2010).
} 
A análise revelou que, do total de dados analisados e considerando-se toda a série de plosivas, $24 \%$ apresentaram alteração no vozeamento, quer desvozeando-se os segmentos vozeados, quer vozeando os não-vozeados. Em relação ao total de dados que apresentaram alteração no vozeamento $(24 \%)$, $35 \%$ foi de vozeamento de segmentos não-vozeados e $65 \%$ de desvozeamento de segmentos vozeados. Esses dados ratificam os resultados de oitiva de Lara (2013), que a levaram a concluir ser o desvozeamento o processo do Hunsrückisch que se estendeu ao português local, uma vez que o desvozeamento se apresenta em muito maior proporção.

Outra observação relevante refere-se à constatação de Lara (2013), com dados levantados de oitiva de plosivas bilabiais, apenas, de que o desvozeamento, não o vozeamento, é o processo variável ainda instanciado no PB falado em Glória. A análise acústica confirma em parte tal constatação: não a quase totalidade, mas $75 \%$ das plosivas alveolares desvozearam. Já o vozeamento foi mais elevado para as velares, com $50 \%$ de ocorrência, conforme Tabela 1 a seguir.

Tabela 1 - Proporção de desvozeamento e vozeamento pelo total de dados alterados em seu vozeamento

\begin{tabular}{l|c|l|c}
\hline \multicolumn{2}{c|}{ Desvozeamento } & \multicolumn{2}{c}{ Vozeamento } \\
\hline Plosiva & Dados: 52 & Plosiva & Dados : 28 \\
\hline$/ \mathbf{b} /-[\mathbf{p}]$ & $(7 / 52) 13 \%$ & $/ \mathbf{p} /-[\mathbf{b}]$ & $(9 / 28) 32 \%$ \\
\hline$/ \mathbf{d} /-[\mathbf{t}]$ & $(39 / 52) 75 \%$ & $/ \mathbf{t} /-[\mathbf{d}]$ & $(5 / 28) 18 \%$ \\
\hline$/ \mathbf{g} /-[\mathbf{k}]$ & $(6 / 52) 12 \%$ & $/ \mathbf{k} /-[\mathbf{g}]$ & $(14 / 28) 50 \%$ \\
\hline
\end{tabular}

O desvozeamento é o processo prevalente, mas em proporções distintas, dependendo do ponto de articulação da plosiva-alvo. Sobre o desvozeamento desenvolveu-se a segunda etapa da análise, a da mensuração do VOT.

A Figura 1 traz o espectrograma da palavra-alvo barato, com a consoante inicial pronunciada como [p]. O desvozeamento da consoante plosiva /b/ para [p], resultando em [pa'rato], pode ser visto na porção destacada entre as linhas pontilhadas que marcam o início e o final da produção da plosiva bilabial. As flechas indicam o VOT dessa plosiva, a da esquerda indica o início da soltura da plosiva e a da direita indica o momento do início da vibração das pregas vocais.

Figura 1 - Forma de onda e espectrograma de [ajspa $]$ no trecho mais barato, evidenciando o desvozeamento de /b/ entre as linhas pontilhadas
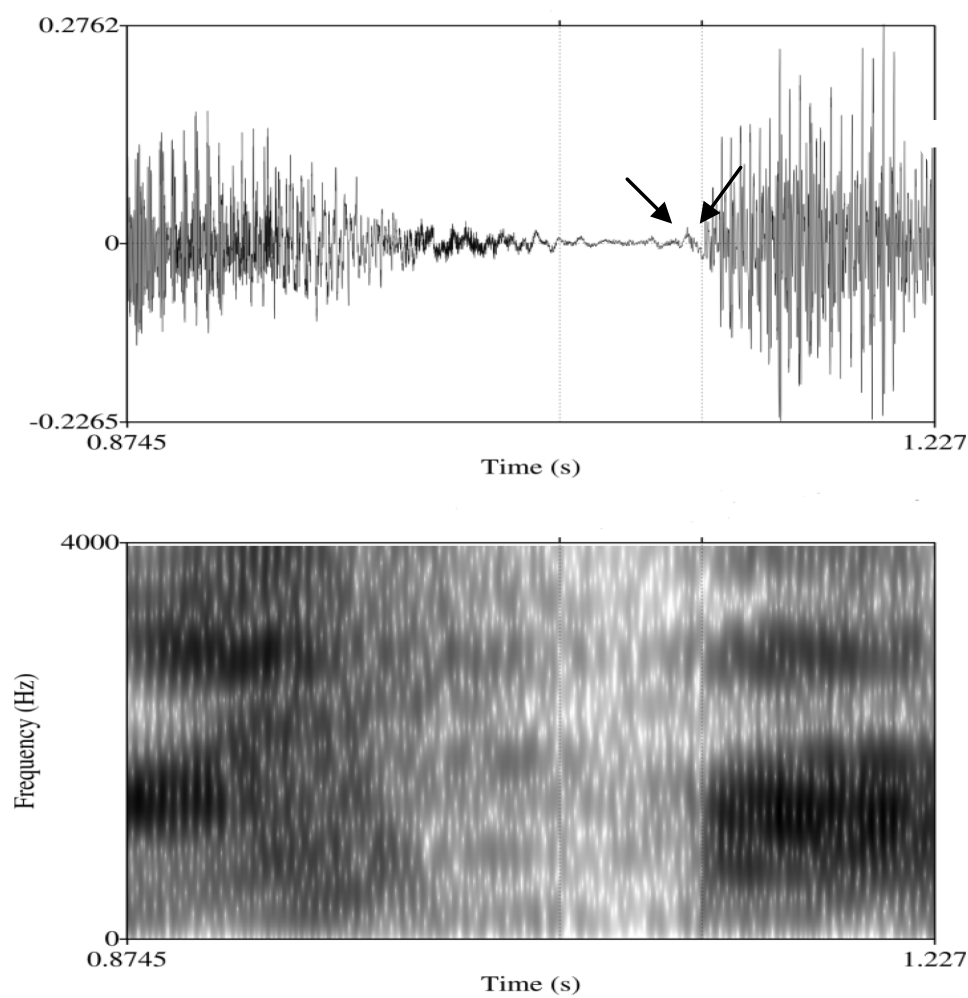
Na Figura 2, observamos o desvozeamento da plosiva alveolar vozeada / d/ produzida como [t] na palavraalvo estudar, resultando em [istu'ta]. Os segmentos [tuta] são exibidos na Figura 2, a partir da forma de onda e do espectrograma. As linhas pontilhadas marcam o início e o final do segmento produzido. As flechas indicam o VOT da plosiva [t] , a da esquerda indica o momento da soltura da oclusão e a da direita o início da vibração das pregas vocais para a produção da vogal que segue essa plosiva.

Figura 2 - Forma de onda e espectrograma de [tuta $]$ no trecho estuda, evidenciando o desvozeamento de /d/entre as linhas pontilhadas


A Figura 3 mostra a forma de onda e o espectrograma da palavra-alvo grava. Nela, verifica-se o desvozeamento da plosiva velar $/ \mathrm{g} /$, produzida como [k], o que pode ser visto na porção destacada pelas linhas pontilhadas, que correspondem ao início e final da consoante. O VOT dessa plosiva é exibido pelas flechas: a da esquerda indica o momento da soltura da oclusão e a da direita o início da vibração das pregas vocais para a produção da vogal contígua à plosiva velar. 
Figura 3 - Forma de onda e espectrograma de [ukra $]$ no trecho tu gravas, evidenciando o desvozeamento $\mathrm{de} / \mathrm{g} / \mathrm{entre}$ as linhas pontilhadas
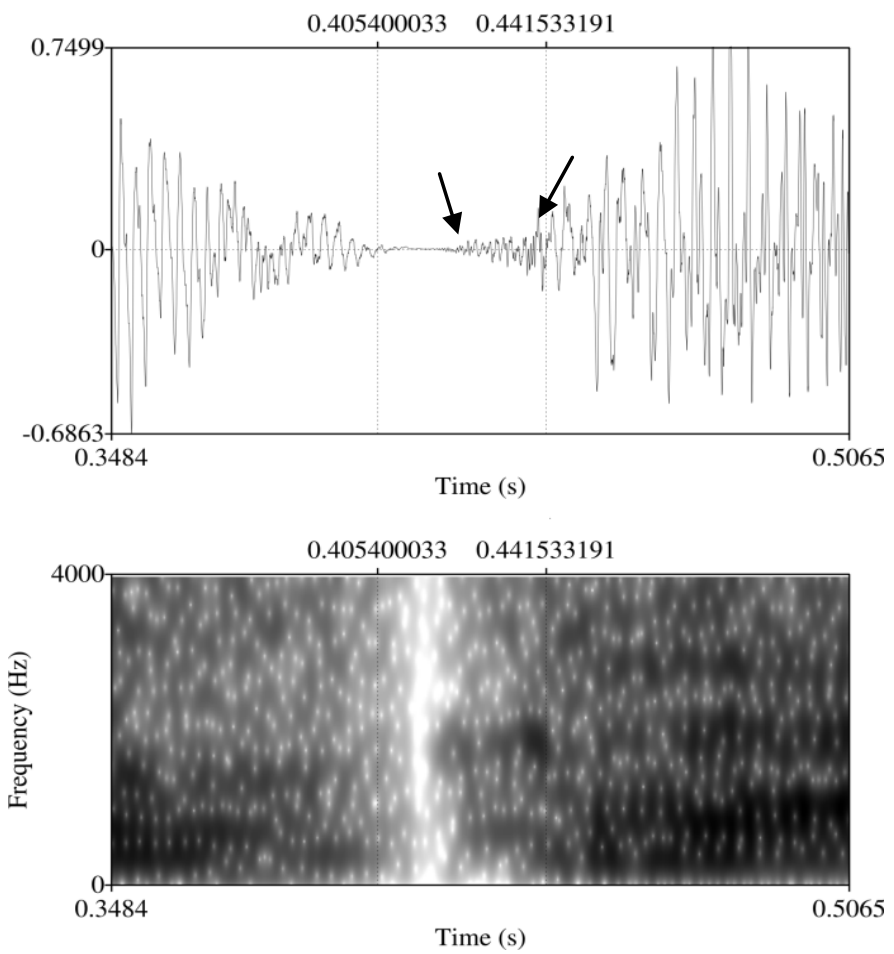

As médias de VOT em sua distribuição (ms) e o coeficiente de variação (CV) nos dados de desvozeamento e de vozeamento estão na Tabela 2 a seguir.

Tabela 2 - Média da duração (ms) do VOT dos segmentos investigados acusticamente

\begin{tabular}{c|c|c|c}
\hline & Média da duração do VOT(ms) & Intervalo & CV (\%) \\
\hline$/ \mathrm{b} /-[\mathrm{b}]$ & $\mathbf{4 4 , 6 9}$ & $19,75-62,66$ & 30 \\
\hline$/ \mathrm{b} /-[\mathrm{p}]$ & $\mathbf{1 1 , 6 9}$ & $7,33-22,66$ & 45 \\
\hline$/ \mathrm{p} /-[\mathrm{p}]$ & $\mathbf{1 3 , 7 0}$ & $4,06-29,58$ & 38 \\
\hline$/ \mathrm{p} /-[\mathrm{b}]$ & $\mathbf{4 4 , 0 3}$ & $20,02-85,88$ & 48 \\
\hline$/ \mathrm{d} /-[\mathrm{d}]$ & $\mathbf{4 5 , 1 8}$ & $17,93-106,94$ & 43 \\
\hline$/ \mathrm{d} /-[\mathrm{t}]$ & $\mathbf{1 4 , 1 2}$ & $5,55-28,53$ & 36 \\
\hline$/ \mathrm{t} /-[\mathrm{t}]$ & $\mathbf{1 5 , 8 8}$ & $1,99-41,85$ & 50 \\
\hline$/ \mathrm{t} /-[\mathrm{d}]$ & $\mathbf{4 5 , 9 2}$ & $26,64-52,07$ & 24 \\
\hline$/ \mathrm{g} /-[\mathrm{g}]$ & $\mathbf{3 6 , 7 0}$ & $19,87-82,42$ & 49 \\
\hline$/ \mathrm{g} /-[\mathrm{k}]$ & $\mathbf{2 0 , 4 6}$ & $12,39-35,08$ & 41 \\
\hline$/ \mathrm{k} /-[\mathrm{k}]$ & $\mathbf{2 4 , 1 3}$ & $7,49-46,15$ & 36 \\
\hline$/ \mathrm{k} /-[\mathrm{g}]$ & $\mathbf{4 3 , 9 3}$ & $20,15-71,20$ & 32 \\
\hline
\end{tabular}

Os resultados do presente estudo são melhor compreendidos no contraste com os obtidos em outras análises, como se vê no Quadro 2: 
Quadro 2 - Médias de VOT encontradas no PB, em línguas minoritárias alemãs e no PB de contato com o Husrückisch

\begin{tabular}{|c|c|c|c|}
\hline $\begin{array}{ll}\text { Autores } & \text { VOTs }\end{array}$ & {$[\mathrm{p}]$} & {$[t]$} & {$[\mathrm{k}]$} \\
\hline $\begin{array}{l}\text { Istre (1983) } \\
(\mathrm{PB})\end{array}$ & $12 \mathrm{~ms}$ & $18 \mathrm{~ms}$ & $38 \mathrm{~ms}$ \\
\hline $\begin{array}{l}\text { Klein (1999) } \\
(\mathrm{PB})\end{array}$ & $\begin{array}{l}17,70 \mathrm{~ms} \\
(5,90: 37,00)\end{array}$ & $\begin{array}{l}16,78 \mathrm{~ms} \\
(6,95: 30,45)\end{array}$ & $\begin{array}{l}37,85 \mathrm{~ms} \\
(20,60: 66,20)\end{array}$ \\
\hline $\begin{array}{l}\text { Alves }(2011) \\
(\mathrm{PB})\end{array}$ & $\begin{array}{l}16,32 \mathrm{~ms} \\
(20,60: 66,20)\end{array}$ & $\begin{array}{l}23,06 \mathrm{~ms} \\
(20,60: 66,20)\end{array}$ & $\begin{array}{l}25,66 \mathrm{~ms} \\
(11,80: 34,88)\end{array}$ \\
\hline $\begin{array}{l}\text { Cristofolini (2013) } \\
\text { (PB) }\end{array}$ & $\begin{array}{l}22,37 \mathrm{~ms} \\
(4,26: 61,62)\end{array}$ & $\begin{array}{l}20,28 \mathrm{~ms} \\
(9,15: 34,72)\end{array}$ & $\begin{array}{l}47,61 \mathrm{~ms} \\
(15,77: 89,88)\end{array}$ \\
\hline $\begin{array}{l}\text { Gewehr-Borella (2010) } \\
\text { (Hunsrückisch) }\end{array}$ & $27,36 \mathrm{~ms}$ & $23,91 \mathrm{~ms}$ & $40,85 \mathrm{~ms}$ \\
\hline $\begin{array}{l}\text { Bandeira }(2010) \\
\text { (Pomerano) }\end{array}$ & $51 \mathrm{~ms}$ & $44 \mathrm{~ms}$ & $76 \mathrm{~ms}$ \\
\hline $\begin{array}{l}\text { Valores de VOT neste estudo } \\
\text { (PB de contato com o Husrückisch) }\end{array}$ & $\begin{array}{l}13,70 \mathrm{~ms} \\
* 11,69 \mathrm{~ms} \\
(4,06: 29,58)\end{array}$ & $\begin{array}{l}15,88 \mathrm{~ms} \\
* 14,12 \mathrm{~ms} \\
(1,99: 41,85)\end{array}$ & $\begin{array}{l}24,13 \mathrm{~ms} \\
\text { * } 20,46 \mathrm{~ms} \\
(7,49: 46,15)\end{array}$ \\
\hline
\end{tabular}

Os valores encontrados neste estudo, para [p t k], produzem um primeiro contraste em sua comparação com os VOTs das plosivas do Hunsrückisch (cf. GEWEHR-BORELLA, 2010): são menores. GewehrBorella (2010, p. 171) afirma que há "na língua de imigração estudada, em início de palavra, apenas os padrões de VOT zero e positivo, ou seja, sem pré-vozeamento, com e sem aspiração”. Isso pode resultar do tipo de dado utilizado, se de criança ou de adulto. A tendência é a de os valores de VOT serem maiores para as crianças e diminuírem à medida que os indivíduos aproximam-se da fase adulta, como observa Cristofolini (2013). Em seu estudo, a autora constatou diferenças nos valores de VOT nos grupos etários, os valores maiores de VOT sendo os do grupo infantil de 6 a 8 anos de idade. Os dados de Gewehr-Borella (2010) são de alunos, de indivíduos em idade escolar (crianças e jovens). Os nossos dados são de uma idosa. Pode estar aí a razão de termos obtido VOTs menores.

Os valores médios de VOT que verificamos contrastam também com aqueles obtidos por Bandeira (2010). Segundo a autora, "considerando-se o fato de que o pomerano ${ }^{7}$ falado em Arroio do Padre $^{8}$ apresenta valores elevados de VOT de $51 \mathrm{~ms}$ para o /p/, 44 ms para o /t/ e $76 \mathrm{~ms}$ para o / $/ \mathrm{k} /$, considera-se que esta seja uma língua de imigração com altos valores de aspiração." (BANDEIRA, 2010, p. 67).

Cogitamos também que a alta velocidade de fala, outro fator de influência sobre o VOT, segundo Cho e Ladefoged (1999), poderia ser a origem da divergência de nossos VOTs, já que I.L, nossa informante, fala muito rapidamente. No entanto, a principal diferença parece ser mesmo o fato de as demais autoras terem analisado dados de crianças em fase de escolarização. Além disso, I.L., adulta bilíngue, relaciona-se por laços fortes na rede social de Glória como sujeitos cujas práticas sociais requerem o uso do PB, não do Hunsrückisch, como vimos na Seção 2. Assim, embora I.L desvozeie plosivas de uma maneira não esperada no PB, ela o faz de forma distinta do Hunsrückisch.

Essa peculiaridade do PB de contato por nós verificada permite pensar que o desvozeamento em Glória e em outras comunidades de perfil similar não resulte da pura transferência de caracteríaticas do Hunsrückisch ao português. Nos termos de Mohanan e Mohanan (2003), corresponde ao padrão do sistema bilíngue, que não é nem o sistema de L1, nem o de L2, mas o sistema que emerge da tensão entre os dois outros.

\footnotetext{
${ }^{7}$ Não há valores de referência para o pomerano europeu, uma vez que essa língua não existe mais na Europa. Também há carência de dados relativos às médias de VOT do pomerano falado em outros lugares do Brasil, como no Espírito Santo.

${ }^{8}$ Arroio do Padre é um pequeno município gaúcho situado ao sul do estado do Rio Grande do Sul, vizinho ao município de Pelotas.
} 


\section{CONCLUSÃO}

O estudo realizado compreendeu revisão de literatura, que registra o desvozeamento das plosivas bilabiais no PB falado por bilíngues PB-Hunsrückisch como um dos traços da língua minoritária transferido para a majoritária. Na literatura consta também que o VOT de plosivas do PB produzidas por crianças bilíngues em idade escolar espelha o da variedade alemã.

A análise acústica empreendida confirmou o desvozeamento percebido de oitiva por Lara (2013). Na fala em $\mathrm{PB}$, os valores de VOT aproximam-se do padrão da língua majoritária $(\mathrm{PB})$, não do padrão da minoritária (Hunsrückisch), mas ainda assim são diferentes do PB, o que sugere ser o sistema bilíngue um sistema com seu próprio estatuto e características, relacionadas à língua minoritária e majoritária, mas não determinadas por essas línguas.

Os valores de VOT encontrados neste estudo não corroboram os de estudos anteriores. No entanto, analisaram-se dados de uma só informante. É necessário expandir a análise, o que se fará em estudos futuros. Por ora, pode-se afirmar que a realização de análise acústica não só confirmou características efetivamente produzidas na fala, como também forneceu elementos para pensar as peculiaridades do sistema de línguas em contato em que a variação fonológica se instancia.

\section{REFERÊNCIAS}

Altenhofen, C.V. A Aprendizagem do Português em uma Comunidade Bilíngue do Rio Grande do Sul: um estudo de Redes de Comunicação em Harmonia. 1990. Dissertação (Mestrado em Letras) - Programa de Pós-Graduação em Letras, Universidade Federal do Rio Grande do Sul, Porto Alegre, 1990.

ALVES, M. A. Production of English and Portuguese voiceless stops by Brazilian EFL speakers. 2011. Dissertação (Mestrado em Letras) - Florianópolis, Universidade Federal de Santa Catarina, 2011.

BANDEIRA, M.T. Diferenças entre crianças monolíngues e multilingues no desempenho de tarefas de funções executivas e na transferência de padrões de VOT (Voice Onset Time) entre as plosivas surdas do pomerano, do português e do inglês. 2010. Dissertação (Mestrado em Letras) - Programa de Pós-Graduação em Letras, Universidade Católica de Pelotas, Pelotas, 2010.

BANDEIRA, M.T.; ZIMMER, M.C. A transferência dos padrões de VOT de plosivas surdas no multilinguismo. Letras de Hoje, v. 46, n. 2, p. 87-95, 2011. Disponível em: http://revistaseletronicas.pucrs.br/ojs/index.php/fale/article/viewFile/7503/6577. Acesso em: 12 jun. 2013.

BOERSMA, P.; WEENINK, D. Praat: doing phonetics by computer [Computer program]. Versão 5.3.51, 2013. Disponível em: <http://www.praat.org/>. Acesso em 20/07/2013.

CHO, T.; LADEFOGED, P. Variation and universals in VOT: evidence from 18 languages. Journal of Phonetics, p. 207-229, 1999.

CRISTOFOLINI, C. Gradiência na fala infantil: caracterização acústica de segmentos plosivos e fricativos e evidências de um período de "refinamento articulatório". 2013. Tese (Doutorado em Linguística). Florianópolis. Universidade Federal de Santa Catarina, 2013.

CRYSTAL, D. Dicionário de linguística e fonética. Rio de Janeiro: Jorge Zahar Editor, 2000.

GEWEHR-BORELLA, S. A influência da fala bilíngue Hunsrückisch- Português brasileiro na escrita de crianças brasileiras em séries iniciais. 2010. 205f. Dissertação (Mestrado em Letras) - Programa de Pós-Graduação em Letras. Universidade Católica de Pelotas, Pelotas, 2010.

HARDCASTLE, W.J. Some observations on the tense-lax distinction in initial stops in Korean. Journal of Phonetics, v. 1, p. 263-272, 1973. 
ISTRE, G.L. Fonologia transformacional e natural: uma introdução crítica. Florianópolis: UFSC, 1983.

KLEIN, S. Estudo do VOT no português brasileiro. 1999. Dissertação (Mestrado em Linguística) Florianópolis, Universidade Federal de Santa Catarina, 1999.

LABOV, W. Sociolinguistic patterns. Philadelphia: University of Philadelphia Press, 1972.

LARA, C.C. Variação fonológica, redes e práticas sociais numa comunidade bilíngue português-alemão do Brasil meridional. 2013. 105 f. Dissertação (Mestrado em Letras) - Programa de Pós-Graduação em Letras, Universidade Federal do Rio Grande do Sul, Porto Alegre, 2013.

LISKER, L.; ABRAMSON, A. A cross-language study of voicing in initial stops: acoustical measurements. Word, v. 20, 1964.

MILROY, L. Language and social networks. 2. ed. Oxford, Blackwell, 1987.

Social Networks. In: CHAMBERS, J. K.; TRUDGILL, P.; SCHILLING-ESTES, N. (Eds.). The handbook of language variation and change. Oxford Blackwell Publishing, 2002.

MOHANAN, T.; MOHANAN, K.P. Towards a Theory of Constraints in OT: emergence of the not-sounmarked in Malayalee English. [Available on Rutgers Optimality Archive, ROA- 416-09100], 2003.

RASO, T.; MEllo, H.; ALTENHOFEn, C.V. Os contatos linguísticos e o Brasil - Dinâmicas préhistóricas, históricas e sociopolíticas. In: MELLO, H.; ALTENHOFEN, C.V.; RASO, T. (Orgs.). Os contatos linguísticos no Brasil. Belo Horizonte: Editora UFMG, 2011.

REIS, M.; NOBRE-OLIVEIRA, D. Effects of perceptual training on the identification and production of English voiceless plosives aspiration by Brazilian EFL learners. In: INTERNATIONAL SYMPOSIUM ON THE ACQUISITION OF SECOND LANGUAGE SPEECH, 5. Proceedings... Florianópolis: UFSC, 2007. p. 398-407.

WEIRICH, H.C.; FERREIRA-GONÇALVES, G. Influência da língua de imigração hunsrǚckisch na produção de plosivas: uma comparação entre bilíngues e monolíngues. In: CONGRESSO DE INICIAÇÃO CIENTÍFICA E 4ª MOSTRA CIENTÍFICA (CIC - UFPEL), 21., Pelotas. CIC UFPelotas, 2012.

Recebido em 24/10/2013. Aprovado em 25/04/2014. 